\title{
Stability of PAM/PEl emulsified gels under HTHS conditions for water shut-off treatment
}

\author{
Abdullah S. Sultan ${ }^{1}$ (]) \\ Received: 31 March 2018 / Accepted: 13 December 2018 / Published online: 19 December 2018 \\ (c) The Author(s) 2018
}

\begin{abstract}
Emulsification has been widely used in the oil industry. The thermal stability of emulsified systems, such as emulsified gels or acids, is critical for the placement success of the emulsified system. Early separation of the system in a tubular well leads to corrosion. In the present study, the stability of emulsified polyacrylamide/polyethylenimine (PAM/PEI) gels is investigated in high-temperature and high-salinity (HTHS) environments. The influences of different parameters such as surfactant concentration, water-oil ratio, salinity, intensity of mixing and temperature on the droplet size and the emulsion thermal stability are studied. The droplet size of the PAM/PEI system, which is emulsified in diesel, decreases, and the separation time increases with increasing mixing speed, surfactant concentration, and salinity. The emulsions with smaller droplets are thermally stable compared with large droplets since the rate of droplet coalescence is low. The effect of emulsion stability on gelation kinetics and gel strength is investigated. The emulsification reduces both the gel strength and the gelation rate. The cross-linking (gelation) rate in the unemulsified PAM/PEI is almost ten times higher than that in the emulsified gels. This gelation process is slow in the case of stable emulsified PAM/PEI solution and is believed to be the result of limited heat and mass transfer. The emulsion stability achieved in this work adds to the current understanding of how to control emulsion stability through different parameters to withstand HTHS environments and how this stability influences the gelation process.
\end{abstract}

Keywords Water in oil emulsion · Thermal stability · Droplet size · Gelation kinetics · Polymeric gel

\section{Introduction}

Emulsification techniques have long been used in various fields (Anderson and Daniels 2003; Friberg et al. 2004; Dean et al. 2009; Kasapis et al. 2009; Osemeahon 2011; Rai and Pandey 2013). In particular, emulsification has been broadly applied in different applications in the oil industry (Ebeltoft et al. 2001; Sayed et al. 2013; Al-Yaari et al. 2014). Emulsification techniques were introduced in the oil industry through the use of emulsified acids in 1933. Emulsified acids were invented to address corrosion problems rather than to improve the stimulation job (Al-Mutairi et al. 2007). Thus, many researchers have comprehensively studied this technique to better understand the advantages and disadvantages

Abdullah S. Sultan

sultanas@kfupm.edu.sa

1 Department of Petroleum Engineering and Center for Integrated Petroleum Research, College of Petroleum Engineering and Geosciences, King Fahd University of Petroleum \& Minerals, Dhahran 31261, Saudi Arabia of emulsified acids (Crenshaw and Flippen 1968; Navarrete et al. 1998; Al-Mutairi et al. 2009). Moreover, the stability and rheological properties of emulsified acids have been extensively investigated by studying the impact of different parameters such as surfactant concentration, dispersed-phase droplet size and acid volume fraction (see Sayed and NasrEl-Din 2011 and references therein).

Emulsification has been used in drilling-fluid formulations (Lawhon et al. 1967; Patel 1999; Ebeltoft et al. 2001), for drag reduction in multiphase flow (Al-Yaari et al. 2014) and well-stimulation applications (Al-Mutairi et al. 2007), and in fracturing treatments for gas wells (Taylor and NasrEl-Din 2001). A cost-effective emulsified xylene additive was developed to improve well productivity and prevent asphaltene deposition (Fattah and Nasr-El-Din 2010), and emulsified chelating agents were developed for permeability enhancement (Sayed et al. 2013). In addition to these applications, a new application of the emulsification technique in oilfields was proposed recently as a means of water control.

Water production is the primary waste stream associated with hydrocarbon exploration and production (Clark 
and Veil 2009). Excessive water production has negative economic, technical, and environmental effects (Hibbeler and Rae 2005; Al Tolaihy et al. 2010). Thus, shutting off or reducing water production is highly desirable. Polymer gels are commonly used for water control for coning problems or multilayered reservoirs (Sparlin 1976; Schneider and Owens 1982; Zaitoun et al. 1999; Kalfayan and Dawson 2004; Seright 2009; El-Karsani et al. 2015a, b). However, the use of polymer gels is associated with a high risk of substantially reducing hydrocarbon production with the reduction in water and is accompanied with high operational costs. Stavland and Nilsson proposed pumping emulsified gels for a water shut-off field application (Stavland et al. 1997, 2006); in this approach, a water-soluble polymer is emulsified into diesel. This system is intended to break into an oleic and a water phase. The oleic phase remains mobile to ensure an open channel for the flow of hydrocarbons, whereas the water phase gels, thereby restricting the flow of formation water.

The breaking and subsequent gelation of the emulsified gels are critical factors in gelant placement success. Thus, suitable separation and a longer gelation time are required, especially for high-temperature reservoirs, to avoid gelation in the tubing during the placement. Limited data have been reported regarding the formulation and stability of emulsified gels. In 2006, Stavland et al. studied the emulsification of polyacrylamide and tert-butyl acrylate (PAtBA) crosslinked with polyethylenimine (PEI) into diesel. The system was loaded into a test tube and then heated at $90{ }^{\circ} \mathrm{C}$ for a given time, and the relative viscosity of the water phase was subsequently measured at $25^{\circ} \mathrm{C}$. The gelation rate was compared with that of a reference cross-linked polymer (not emulsified). A slight increase in the gel strength was calculated when the standard cross-linked polymer was tested instead of the emulsified polymers, although no data on the gel strength were presented. A more cost-effective homopolymer, polyacrylamide (PAM), was found to be a suitable replacement for PAtBA (Al-Muntasheri et al. 2007; El-Karsani et al. 2015a, b). In a recent publication, our group studied the gelation kinetics of an emulsified PAM/PEI system using a thermal analysis technique (Mohamed et al. 2015).

A colloidal dispersion of two or more partially or completely immiscible fluids is known as an emulsion (Lachman et al. 1986; Becher 1996; Tamilvanan et al. 2016); i.e., a dispersed phase is suspended in an external (continuous) phase in the form of droplets. Hence, an emulsion is thermodynamically unstable in nature (Weiss 2002; Tamilvanan et al. 2016) due to the interaction between hydrophilic and hydrophobic molecules at the surface of each droplet. If an emulsifier is introduced into a 2-phase system, the system tends to stabilize and form a dispersed phase and a continuous phase since the emulsifier retards the breakage of the system through, for example, flocculation or coalescence (Becher 1996; Binks and Rocher 2009). Droplets coalesce by creating three-dimensional (3D) cross-linked networks of aggregates on the surface of the droplets.

Emulsifiers are believed to be able to form a viscoelastic barrier (Guo et al. 2006). The rigid interfacial films on the surface of dispersed-phase droplets in emulsions have been reported to prevent coalescence (Kokal 2005). The stability of the emulsion depends on various parameters, including the external phase viscosity, water oil ratio (WOR), the presence of steric films on the droplets, the droplets' size, the physical nature of the interfacial film, mixing time and the temperature (Joshi et al. 2012). The stability of the emulsion is associated with the quantity of emulsifier adsorbed at the interface. With the adsorption of more surfactant, the interfacial tension decreases and the emulsifier molecules act as a layer slowing the droplets' coalescence (Becher 1996; Joshi et al. 2012; Rai and Pandey 2013). Moreover, water salinity has been established to play an important role in stabilization. For example, for oil in water $(\mathrm{O} / \mathrm{W})$, an increase in the water salinity $(\geq 5000 \mathrm{ppm})$ resulted in a lower interfacial tension, as evidenced by the smaller double layer (Aveyard et al. 1989). A further increase in salinity resulted in phase inversion to water in oil (W/O) (Winsor 1948). Additionally, an inhomogeneous distribution of the dispersed droplets of an $\mathrm{O} / \mathrm{W}$ emulsion was observed when the external phase salinity was increased from zero ppm to $5000 \mathrm{ppm}$; this phenomenon was found to be related to a passive interaction between the emulsifier and water charges (Al-Yaari et al. 2013a). Conversely, at high salinity ( $\geq 20,000 \mathrm{ppm}$ ), enhancements were observed in both the W/O emulsion viscosity and the repulsive forces between the droplets of the dispersed phase (water). These enhancements led to an increase in the water droplets' double layer (Al-Yaari et al. 2013b). This phenomenon has been proposed to be caused by an increase in the interfacial tension (Aveyard et al. 1989). Moreover, an increase in water-dispersed droplets' film rigidity is expected when the aqueous-phase salinity is increased (Mclean and Kilpatrick 1997). This argument is consistent with arguments in the literature (Al-Yaari 2013a). Furthermore, for W/O emulsions, the hydrophilicity of the medium will increase with decreasing salinity, leading to an increase in emulsion stability (Strassner 1968; Montserrat Fortuny et al. 2007). It was observed recently that salt increases the stability of the emulsions by reducing the growth in the droplet size (Ling et al. 2018). Emulsion stability is also linked to the intensity of mixing. For emulsified acids in the oleic phase, high shearing leads to a fine emulsion, whereas low shearing leads to a coarse emulsion. Moreover, the droplet size and the specific surface area were found to increase with increasing concentration of emulsifier and to decrease with increasing acid volume fraction (AlMutairi et al. 2007).

Forming a stable emulsion to meet the requirements of oilfield applications is not a simple task due to the inherent 
Table 1 Ethoxylated amides, chemical and physical properties

\begin{tabular}{ll}
\hline Characteristics & \\
\hline IUPAC & $\begin{array}{c}\text { Bis(2-hydroxye- } \\
\text { thyl)oleylamine }\end{array}$ \\
Form & Solution, $20^{\circ} \mathrm{C}$ \\
Viscosity & $150 \mathrm{mPa} \mathrm{s}, 20^{\circ} \mathrm{C}$ \\
Density & $905 \mathrm{~kg} / \mathrm{m}, 20^{\circ} \mathrm{C}$ \\
HLB & 10.1 \\
\hline
\end{tabular}

Table 2 Make-up water chemical analysis

\begin{tabular}{lccc}
\hline Ion & \multicolumn{3}{l}{ Brine type and concentration, $\mathrm{mg} / \mathrm{L}$} \\
\cline { 2 - 4 } & Formation brine & Sea water & $\begin{array}{l}\text { Field mixing } \\
\text { water (FMW) }\end{array}$ \\
\hline $\mathrm{Na}^{+}$ & 59,300 & 18,300 & 175 \\
$\mathrm{Ca}^{2+}$ & 23,400 & 650 & 46 \\
$\mathrm{Mg}^{2+}$ & 1510 & 2083 & 112 \\
$\mathrm{SO}_{4}{ }^{2-}$ & 110 & 4290 & 377 \\
$\mathrm{Cl}^{-}$ & 137,000 & 32,200 & 266 \\
$\mathrm{HCO}_{3}{ }^{-}$ & 353 & 120 & 146 \\
Total dissolved $^{2}$ & 221,673 & 57,642 & 1,122 \\
solids & & & \\
\hline
\end{tabular}

${ }^{\mathrm{a}}$ Sum of the concentrations of the ions

instability of emulsions. Additionally, the applications are becoming increasingly demanding (HTHS), resulting in the necessity to develop a deeper understanding of the emulsification mechanism. The main goal of this work is to study the impact of different factors on the thermal stability of emulsified PAM/PEI gels and how thermal stability affects the emulsified gel kinetics and gel strength. Furthermore, the relationship between thermal stability and the emulsified gel droplet size is investigated.

\section{Experimental studies}

\section{Materials}

The surfactant ethoxylated amides (AkzoNobel) was used as an emulsifier; its chemical and physical properties are shown in Table 1. Three types of brine were used for the water phase; the brine types and their corresponding concentrations of dissolved ions are shown in Table 2. A representative diesel $\left(814.6 \mathrm{~kg} / \mathrm{m}^{3}\right)$ similar to that used in oilfields for preparing emulsified acids was used. Two aqueous polymer solutions supplied by SNF Florger, PEI as cross-linker and PAM, were used without further treatment. The physical and chemical properties of the polymers are reported elsewhere (El-Karsani et al. 2015a, b).

\section{Procedure and instrumentation}

A high-performance dispersing homogenizer instrument (Ultra-Turrax T50 Basic) equipped with a variable-speed drive with six different speeds (500-10,000 rpm) was used to prepare the polymer gels and emulsified gels. The droplet size measurement was performed using a Leica DM2000 microscope and a FRITSCH laser particle-size analyzer (LPSA) to investigate the effect of droplet size on emulsion stability. The LPSA measurement range is $0.01-600 \mu \mathrm{m}$. GL-18 high-temperature disposable soda-lime-glass test tubes $(18 \times 180 \mathrm{~mm})$ with an approximate volume of $32 \mathrm{~mL}$ and an operating temperature of $180^{\circ} \mathrm{C}$ were used. The hightemperature tubes were sealed with a screw-cap and a rubber seal case to prevent evaporation. The lack of evaporation was confirmed by comparing the initial and final volumes of each sample at the end of the experiment. A laboratory oven (Fisher Isotemp 350G series 300, temperature range: ambient to $300{ }^{\circ} \mathrm{C}$ ) was used to study the emulsion separation-specifically, the separated volume fraction of the phases versus time. A high-pressure cell mounted on the rheometer was used to perform all of the dynamic oscillatory measurements in the temperature range from 120 to $150{ }^{\circ} \mathrm{C}$ $\left(248-302^{\circ} \mathrm{F}\right)$ and at a pressure of $34.47 \mathrm{bar}(500 \mathrm{psi})$, which is much higher than the water vapor pressure at $150{ }^{\circ} \mathrm{C}(\sim 70$ psi). Hence, water was in the liquid phase. Pressure was not expected to affect the gels' strength since the role of pressure was to keep the liquid in solution; the strain used was within the linear viscoelastic range. The dynamic measurements were conducted at a fixed strain of $10 \%$ and a frequency of $1 \mathrm{~Hz}(\mathrm{~Hz})$; these conditions have been previously demonstrated to be within the linear viscoelastic range for PAM/ PEI (El-Karsani et al. 2015a, b).

\section{Emulsified gel preparation}

Emulsified polymer gels solution was prepared in a systemic way to ensure the reproducibility of the systems. The polymer gels were prepared by adding a specific amount of PAM to water (either sea water or field mixing water) while stirring. Then the required amount of cross-linker (PEI) was added drop wise, the mixture kept under continuous stirring for an additional $10 \mathrm{~min}$ to acquire a homogenous solution. This blend is referred to as gelant. The emulsified system was prepared with ethoxylated amides surfactants. The emulsifier (at a specific concentration) was added to the diesel-phase. The emulsifier was given enough time to mix in the diesel thoroughly. Then, the desired volume of the water phase gelant $(70 \mathrm{vol} \%)$ was slowly added to the hydrocarbon phase (30 vol \%, diesel and emulsifier solution) while continuous agitation was performed for an extra 5 min until a homogenous emulsion obtained (Mohamed et al. 2015).

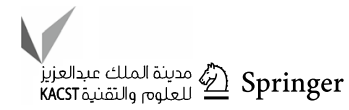




\section{Results and discussion}

To investigate the influence of different factors on the thermal stability and droplet size, we prepared emulsified gel samples at ambient temperature $\left(25^{\circ} \mathrm{C}\right)$. A specimen of each sample was used for particle-size analysis and microscopic observation. Simultaneously, the sealed case high-temperature test tube was used to study the thermal stability, where the separated volume fraction of oil and water phases was observed at a specific temperature. Notably, after 1 week, no water separation was observed in any of the samples.

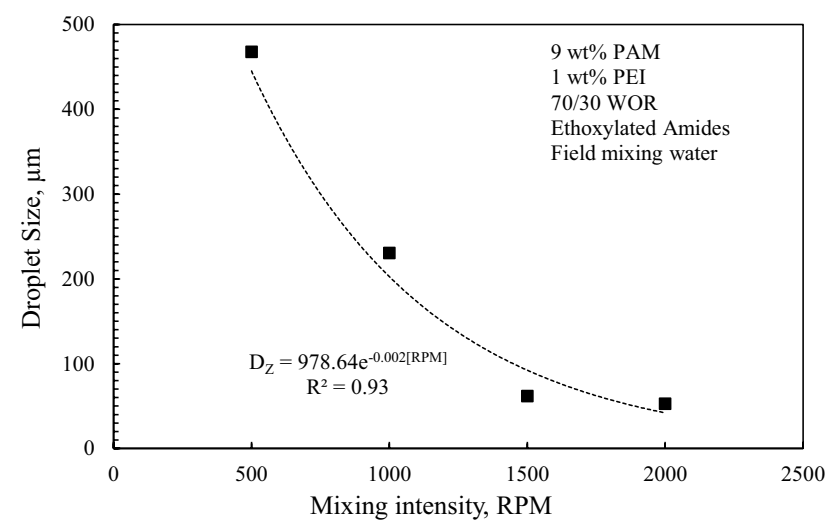

Fig. 1 Droplet size of the emulsified gels at different mixing speeds at $\left(25^{\circ} \mathrm{C}\right)$, as measured by LPSA

\section{Effect of mixing intensity}

To study the influence of mixing speed, we prepared four emulsified gel samples at different mixing speeds ranging from 500 to $2000 \mathrm{rpm}$. As shown in Figs. 1, 2 and 3, the droplet size decreased with increasing mixing speed. The droplet size decreased from 467.67 to $61.65 \mu \mathrm{m}$ (i.e., $~ 87 \%$ decrease, or a factor of 7.6) when the stirring speed was increased from 500 to $1500 \mathrm{rpm}$. However, when the mixing speed was increased from 1500 to $2000 \mathrm{rpm}$, a slight decrease in droplet size from 61.65 to $52.58 \mu \mathrm{m}$ (i.e., $~ 15 \%$ decrease, or a factor of 1.2) was observed. Furthermore, the droplet size distribution was monodispersed at $2000 \mathrm{rpm}$, in contrast to the polydisperse distribution at the lower mixing

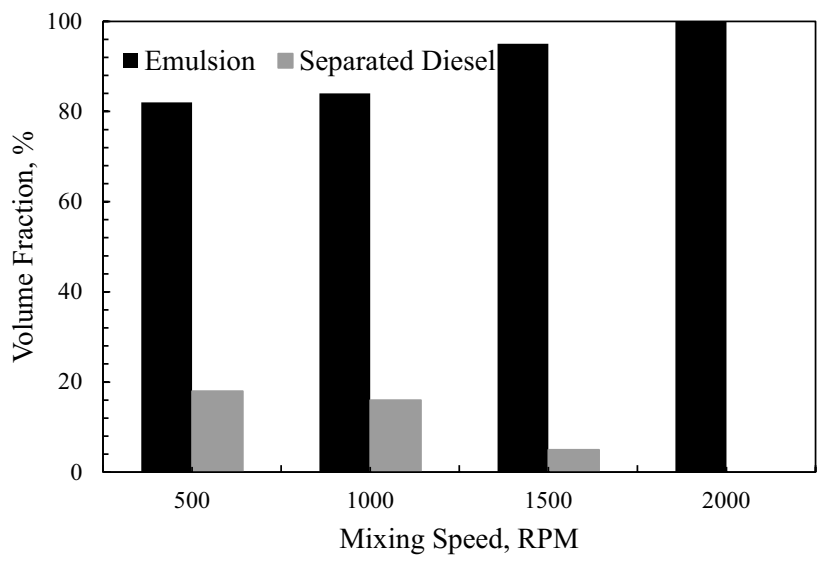

Fig. 3 Volume fraction of the emulsified gels at different mixing speeds after 1 week at $25^{\circ} \mathrm{C}$
Fig. 2 Effect of mixing speed on the droplet size after 1 week at $25^{\circ} \mathrm{C}$, as observed microscopically: a $500 \mathrm{rpm}$, b 1000 rpm, c $1500 \mathrm{rpm}$ and d 2000 rpm

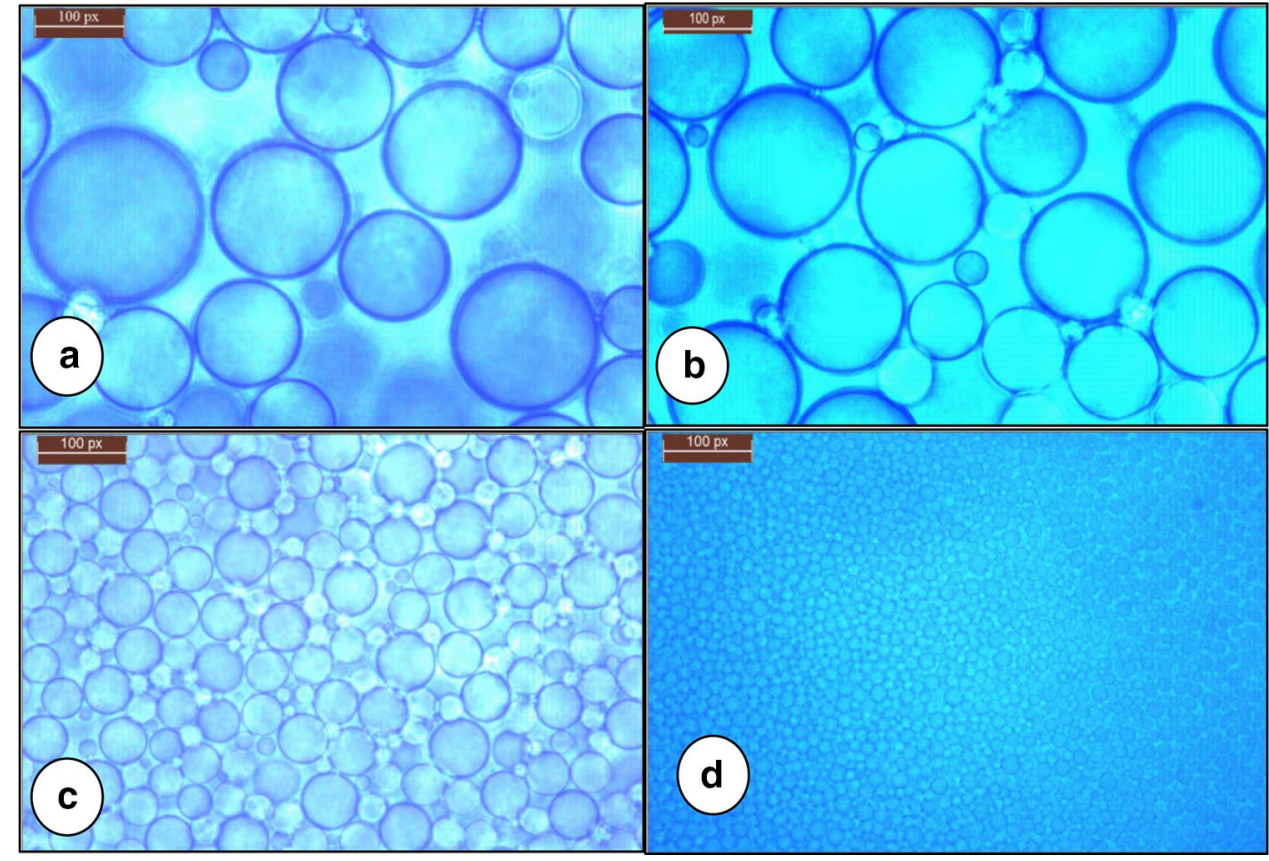


speed (see Fig. 2). In addition, a visual increase in viscosity was observed with the increase in mixing speed, in agreement with previously reported observations (Al-Mutairi et al. 2007). Figure 3 indicates that the emulsified system stability increased with increasing mixing speed. No separation occurred in emulsions prepared at $2000 \mathrm{rpm}$, whereas $18 \%$ of the diesel separated when the mixing speed was $500 \mathrm{rpm}$. This enhancement in the stability was likely caused by a reduction in droplet size and the slow coalescence and sedimentation rate at high mixing rates (see Fig. 2). The effect of the mixing intensity on the droplet size was correlated in the following form: $D_{\mathrm{Z}}=a \mathrm{e}^{\mathrm{b}[\mathrm{RPM}]}$, where $D_{\mathrm{Z}}$ is the droplet size in $\mu \mathrm{m}, \mathrm{RPM}$ is the mixing speed, and $a$ and $b$ are constants.

\section{Effect of salinity}

A representative field-mixing composition-specifically, sea and formation brines-was used to study the influence of water-phase salinity. Note that the field-water salinity was not sufficient to produce a W/O emulsion; thus, $2 \mathrm{wt} \%$ $\mathrm{KCl}$ was added to the field water, resulting in an increase of salinity from 1122 to $21,122 \mathrm{mg} / \mathrm{L}$. Three emulsified gels were formed using different water-phase salinity levels in the range from 21,122 to 221,673 mg/L. As appears in Fig. 4, the droplet size slightly decreased with increasing salinity. The droplet size decreased from 61.65 to $55.46 \mu \mathrm{m}$ (i.e., an $\sim 10 \%$ decrease) when the water-phase salinity was increased from 21,122 (field) to $221,673 \mathrm{mg} / \mathrm{L}$ (formation). Figure 5 shows that insignificant increases/decreases in the stability were realized when the formation brine was used instead of the field water. Conclusively, no further increase in the stability was recorded when the salinity was increased beyond $20,000 \mathrm{ppm}$. This observation is explained by the increase in the repulsive forces between the dispersed phase (here,

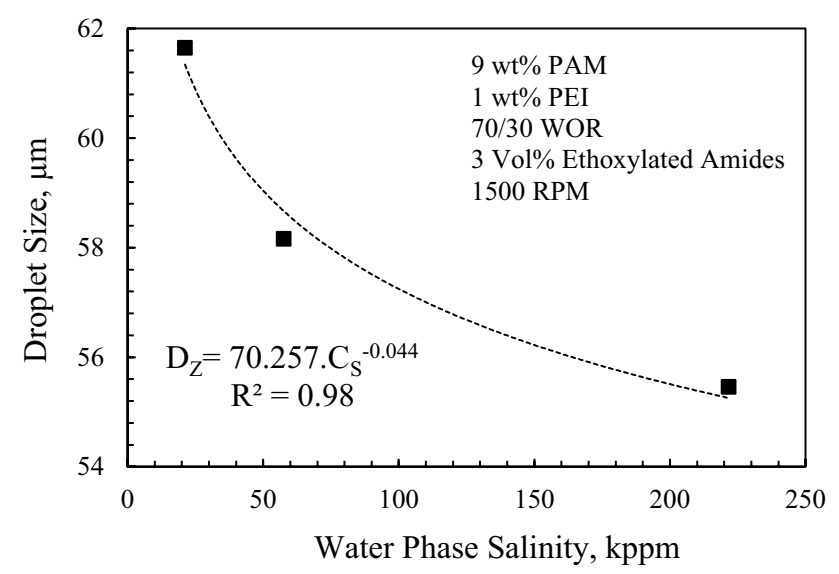

Fig. 4 Droplet size of the emulsified gels for different salinities at $25^{\circ} \mathrm{C}$, as measured by LPSA

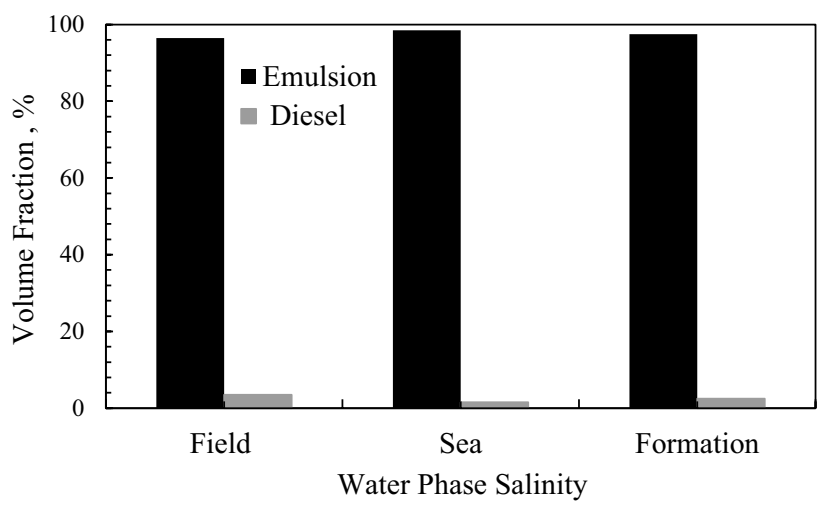

Fig. 5 Volume fractions for the emulsified gels at different salinities after 1 week at $25^{\circ} \mathrm{C}$

brine) droplets, leading to an increase in the brine droplets' double layer. Consequently, interfacial tension between the brine droplets will increase as a result of the increase in hydrophilicity, eventually causing the rate of droplet coalescence to decrease. The increase in stability with increasing salinity, as shown in Fig. 5, is in agreement with previously reported results (Aveyard et al. 1989; McLean and Kilpatrick 1997; Al-Yaari et al. 2013a). The relationship between the brine salinity and the droplet size was modeled in the form of $D_{\mathrm{Z}}=a C_{\mathrm{S}}^{\mathrm{b}}$, where $D_{\mathrm{z}}$ is the droplet size in $\mu \mathrm{m}, C_{\mathrm{S}}$ is the salt concentration, and $a$ and $b$ are constants (see Fig. 4).

\section{Effect of emulsifier concentration}

The impact of the emulsifier dosage was studied through employing ethoxylated amides as an emulsifier; three emulsified gel specimens were produced with different surfactant concentrations in the range from 1 to 6 vol\%. Figure 6 shows that the droplet size decreased with increasing emulsifier concentration: the droplet size decreased from 467.98 to

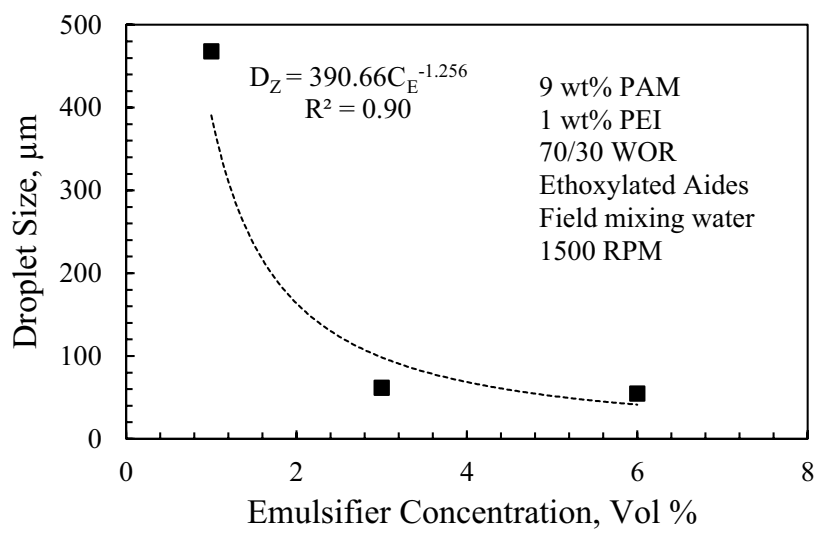

Fig. 6 Droplet size of the emulsified gels at different emulsifier concentrations at $25^{\circ} \mathrm{C}$ 
$61.65 \mu \mathrm{m}$ (i.e., an $\sim 87 \%$ decrease, or a factor of 7.6 ) as the surfactant concentration was increased from 1 to $3 \mathrm{vol} \%$, resulting in a $45 \%$ decrease in the volume of the separated diesel. An additional increase in the concentration from 3 to 6 vol\% resulted in a 90\% decrease in the separated diesel fraction (Fig. 7). The increase in stability can be explained by the amount of emulsifier adsorbed at the interface, where emulsifier molecules act as a layer that inhibits the coalescence of droplets. Adsorption of more emulsifier molecules leads to a decrease in the interfacial tension between the dispersed and continuous phases, thus increasing the stability. The relationship between the emulsifier concentration $\left(C_{\mathrm{E}}\right)$ and the droplet size $\left(D_{Z}\right)$ was modeled as shown in Fig. 6.

\section{Effect of water fraction}

To examine the effect of the water-to-oil ratio (WOR), three emulsified gels samples were prepared. PAM and PEI at concentrations of 9 and $1 \mathrm{wt} \%$, respectively, were used in the preparation of the gelant at different phase fractions in the range from 30 to $70 \%$. As shown in Fig. 8a, b, the droplet size increased with increasing water-phase fraction and decreasing oil-phase fraction. The droplet size increased from 15.24 to $61.65 \mu \mathrm{m}$ (i.e., $~ 400 \%$ increase, or a factor of 4) when the water-phase fraction was increased from 30 to $70 \%$ (the oil-phase fraction decreased from 70 to $30 \%$ ). Figures 9 and 10 show that the stability of the emulsified gels increased with increasing water-phase fraction (decreasing oil-phase fraction): $5 \%$ of the diesel separated and $65 \%$ separation was observed when a 70/30 WOR was used to form the system.

Interestingly, poor stability was observed at smaller droplet sizes, in contrast to earlier observations. This observation may indicate that additional factors control the emulsion stability or perhaps that the interaction between the water-phase molecules dictates system stability. As previously discussed,

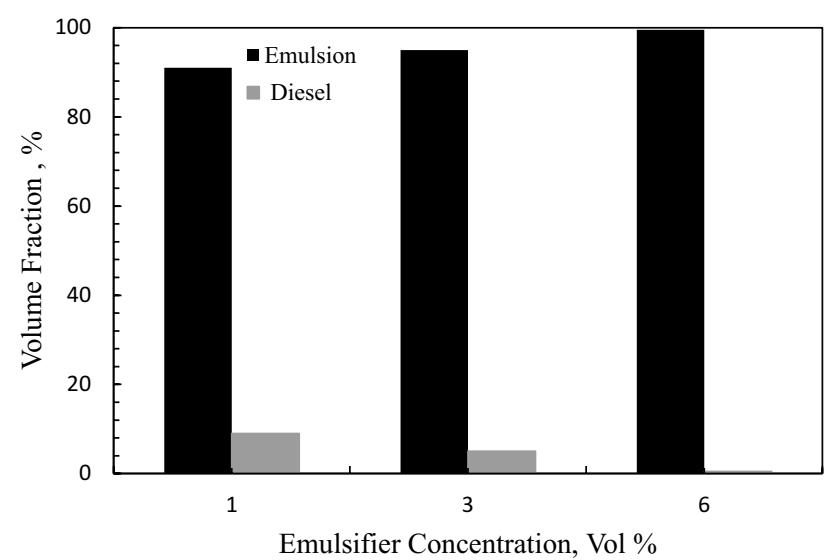

Fig. 7 Volume fraction of the emulsified gels at different emulsifier concentrations after 1 week at $25^{\circ} \mathrm{C}$

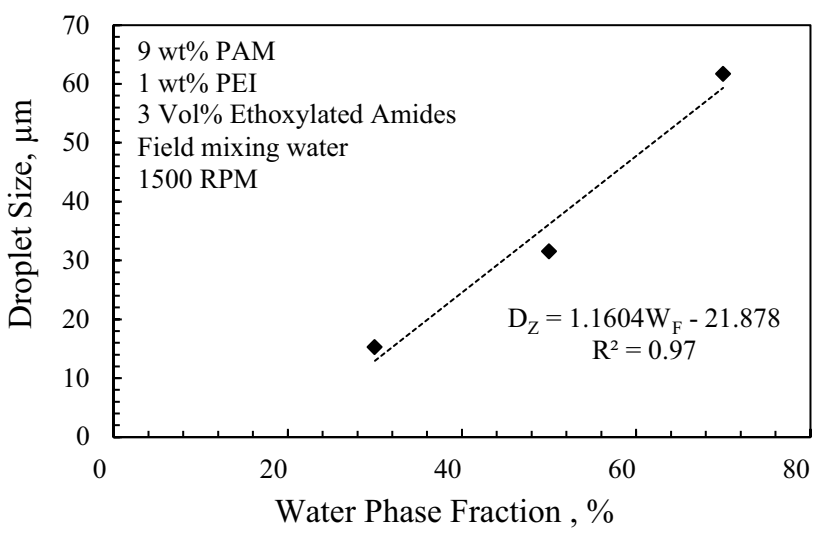

Fig. 8 Droplet size of the emulsified gels at different water-phase fractions at $25^{\circ} \mathrm{C}$

the salinity controls the interaction between the dispersedphase molecules. High stability was perceived at a high salinity due to the increase in the repulsive forces among brine molecules. Hence, at high water fraction, the effect of the salinity is more pronounced. The correlation between the WOR and the droplet size was linear, as shown in Fig. 8a, b, where WF and OF represent the water- and oil-phase fractions, respectively.

\section{Effect of temperature}

For the investigation of the influence of the temperature on the stability, four solutions containing (9/1) wt\% PAM/PEI were formed at ambient temperature $\left(25^{\circ} \mathrm{C}\right)$. The effect of temperature was thereafter examined at various temperatures in the range from 25 to $120^{\circ} \mathrm{C}\left(77-248^{\circ} \mathrm{F}\right)$. Figure 11 indicates that the emulsified system stability decreased with increasing temperature. Approximately $3 \%$ of the diesel had separated after $1 \mathrm{~h}$, and no water-phase separation was observed when the oven temperature was increased

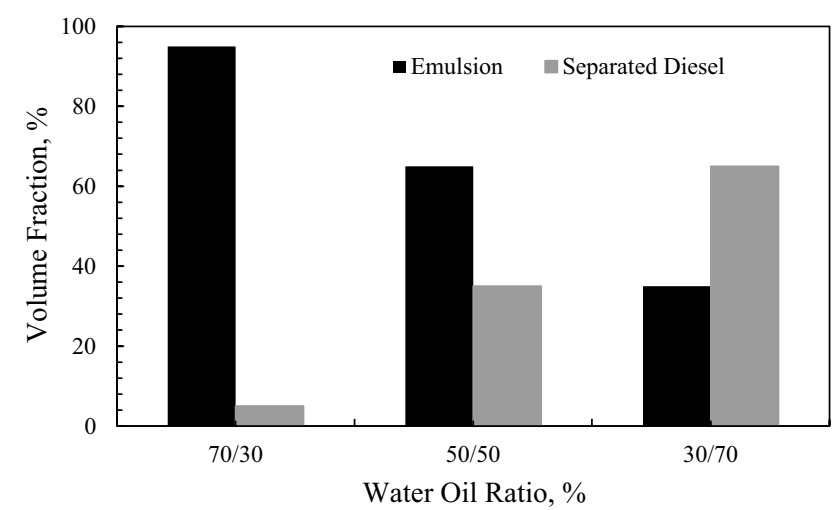

Fig. 9 Volume fraction of the emulsified gels at different WOR after 1 week at $25^{\circ} \mathrm{C}$ 
Fig. 10 Effect of WOR on the stability after 1 week at $25^{\circ} \mathrm{C}$ : a 70/30 WOR, b 50/50 WOR and c $30 / 7070 / 30 \mathrm{WOR}$

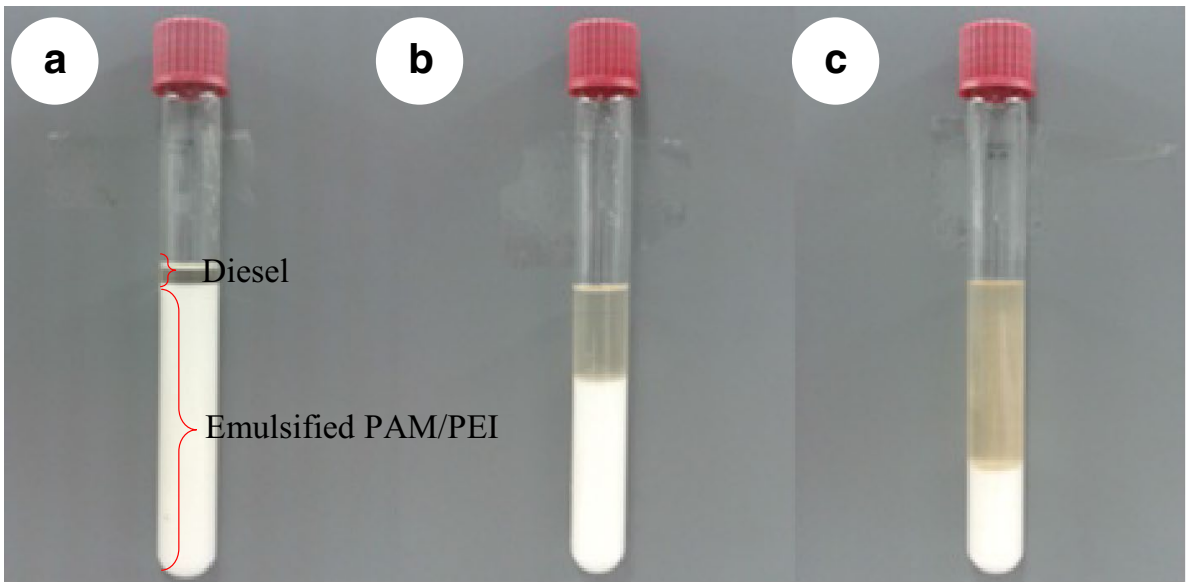

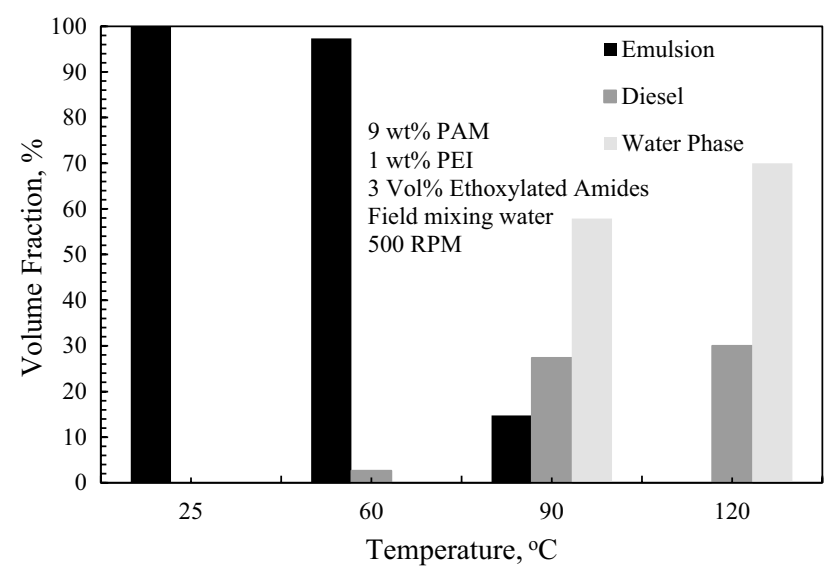

Fig. 11 Volume fraction of the emulsified gels at different temperatures after $1 \mathrm{~h}$

from $25^{\circ} \mathrm{C}\left(77^{\circ} \mathrm{F}\right)$ to $60^{\circ} \mathrm{C}\left(140^{\circ} \mathrm{F}\right)$. Moreover, $30 \%$ of the diesel and $70 \%$ of the water phase was separated after $1 \mathrm{~h}$ when the temperature was increased from $60^{\circ} \mathrm{C}\left(140^{\circ} \mathrm{F}\right)$ to $120^{\circ} \mathrm{C}\left(248^{\circ} \mathrm{F}\right)$. This result represents a $91 \%$ increase in the fraction of the separated diesel (or a factor of 11.4), which reflects negatively on the stability, as shown in Fig. 11. This effect on the stability may be due to the relationship between the temperature and the rate of coalescence; i.e., the coalescence is slow at low temperature. The increase of temperature results in a progressive increase in coalescence and in the sedimentation rate, leading to further separation.

\section{Effect of stability on gel strength}

Here, the influence of emulsification and separation time on gel strength and gelation kinetics is investigated. Three systems - one polymeric gel and two emulsified gel formulations (with different separation times)-were prepared in field missing water (FMW) at ambient temperature, each containing PAM/PEI (9/1) wt $\%$. The effect of emulsification

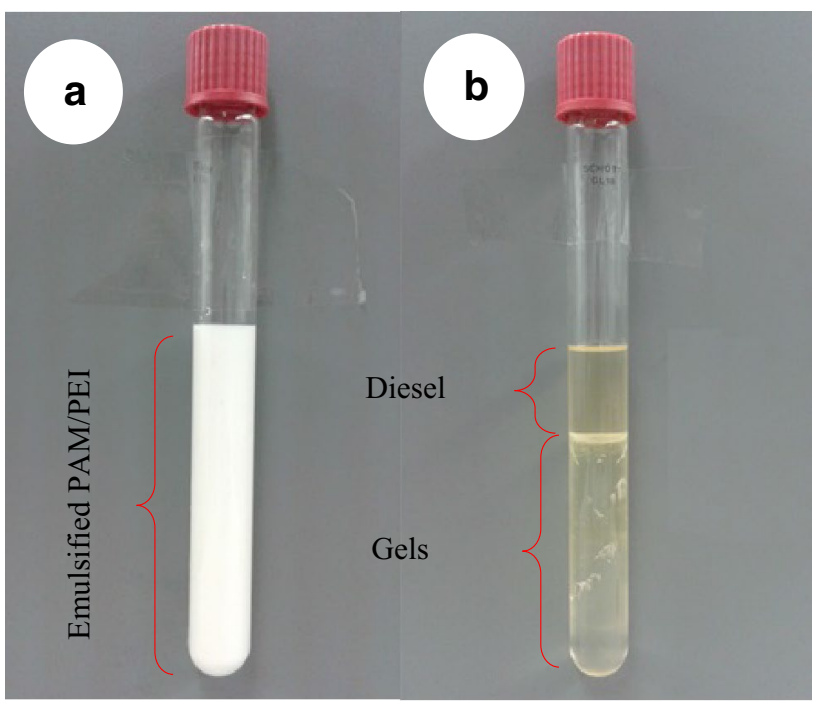

Fig. 12 Emulsified gel formulations: a no separation and $\mathbf{b}$ complete separation

was then studied at $120^{\circ} \mathrm{C}\left(248^{\circ} \mathrm{F}\right)$. The two emulsified gel formulations were prepared as follows: in the first formulation, the emulsified gels were very stable, and no separation occurred during the test time, whereas the second formulation was fully separated within $60 \mathrm{~min}$, as illustrated in Fig. 12. Three characteristic regimes are detected in the results, as shown in Fig. 13. An induction stage in which a low storage modulus $G^{\prime}(t)$ was measured due to the low elasticity of the sample, whereas in the subsequent period, a sharp increase in $G^{\prime}(t)$ values was observed. The inflection point is correlated with the onset of gelation.

The third regime, signified by the plateau in the storage modulus values $\left(G_{\mathrm{e}^{\prime}}\right)$, is associated with gel strength. Figure 13 shows that a longer gelation time was detected with emulsification. The gelation time was very close in the cases of polymeric gels (97 $\mathrm{min}$ ) and the emulsified gels (111 $\mathrm{min}$ ), where the sample completely separated within 


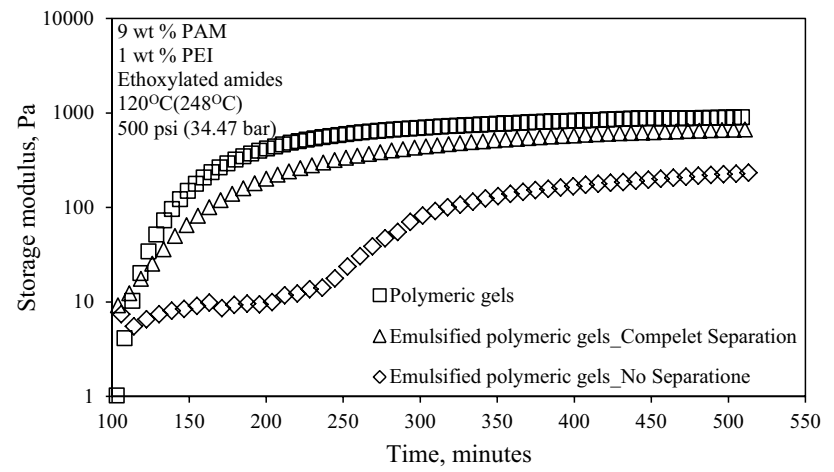

Fig. 13 Effect of emulsification on gelation

$1 \mathrm{~h}$. Moreover, gelation onset occurred at $228 \mathrm{~min}(2 \mathrm{~h}$ later) for the very stable emulsified gel (no separation). Furthermore, a low gel strength was measured with emulsification. The $G_{\mathrm{e}}{ }^{\prime}$ decreased from 882.6 to $748.7 \mathrm{~Pa}$ (i.e., $\sim 15 \%$ decrease) for emulsified PAM/PEI emulsified with complete separation. The emulsification effect was found to be more evident when the stable emulsified system (no separation) was studied, where $G_{\mathrm{e}}{ }^{\prime}$ decreased from 882.6 to $348.5 \mathrm{~Pa}$ (i.e., $~ 61 \%$ decrease), as shown in Fig. 13.

The aforementioned can be explained on the basis of the gelation kinetics. The gel strength increased with increasing temperature via cross-linking; thus, a low gel strength was measured when PAM/PEI was emulsified into the oleic phase via the low cross-linking density. This low gel strength may be due to the reduced heat transfer to the PAM/PEI in the case of emulsification; the results indicate that this reduced heat transfer will be the situation for the emulsified system until complete separation is achieved. Finally, the emulsification was found to reduce the gel strength and to lower the gelation rate. Nevertheless, the ultimate gel strength could theoretically be achieved if sufficient time is allowed for the emulsified system to fully break. Hence, the control of emulsification (separation time) is critical in treatment design in terms of gel strength and gelation time.

\section{Effect of stability on gelation kinetics}

The gelation kinetics of the polymeric gels and two emulsified gels during an isothermal regime were studied on the basis of the rheological data and the Avrami model, as discussed in detail elsewhere (Mohamed et al. 2015); the solution of Avrami's equation in the linear form is:

$\ln \left(-\ln \left(1-x_{(t)}\right)\right)=m \ln t+\ln k_{(t)}$,

where $\mathrm{m}$ is an Avrami exponent associated with the gelation mechanism (nucleation), $k_{(t)}$ is the rate constant, $\mathrm{t}$ is the time during gelation and $x_{(t)}$ is the relative gelation, which is defined elsewhere as (El-Karsani et al. 2014):

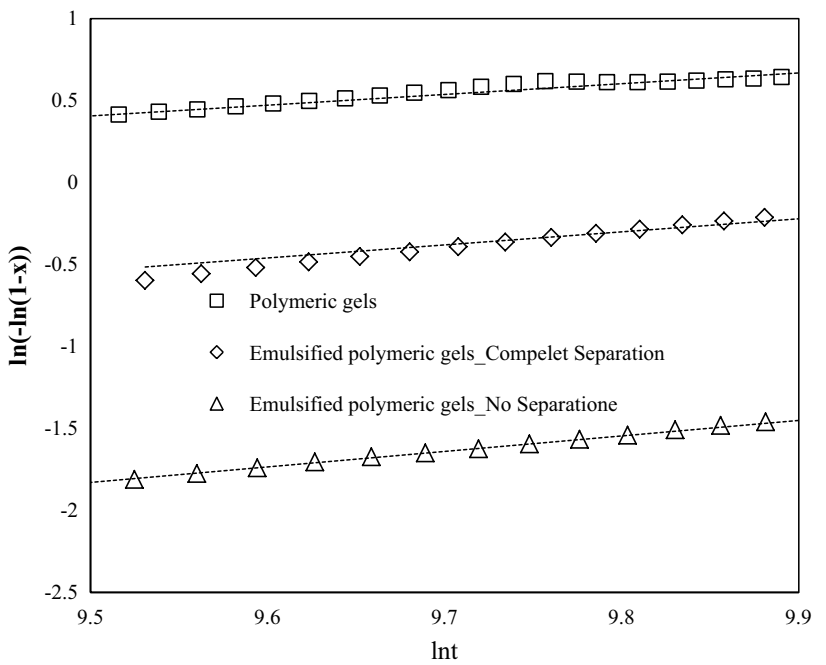

Fig. 14 Avrami's model for the isothermal regime

$x_{(t)}=\left(G_{(t)}^{\prime}-G_{(0)}^{\prime} / G_{(\infty)}^{\prime}-G_{(0)}^{\prime}\right)$,

where $G_{(0)}^{\prime}, G_{(t)}^{\prime}$ and $G_{(\infty)}^{\prime}$ are the storage modulus at the onset of the gelation, the storage modulus at time $t$, and the ultimate equilibrium storage modulus, respectively. The results of isothermal regime analysis for the polymeric gels and the emulsified gels are shown in Fig. 14. From the Avrami model, the values of $\mathrm{m}$ are calculated as $0.70,0.79$, and $\sim 1$, and the reaction rate constants, $k$, are $2.97 \times 10^{-3} \mathrm{~min}^{-1}$, $3.05 \times 10^{-4} \mathrm{~min}^{-1}$, and $2 \times 10^{-5} \mathrm{~min}^{-1}$ for the polymeric gel and the emulsified gels with complete separation and no separation, respectively. These results indicate that the crosslinking (gelation) rate in the unemulsified PAM/PEI is almost ten times higher than that in the emulsified gels with complete separation. This behavior is more pronounced in the case of no separation.

\section{Conclusions}

In general, this work provided insight into the factors that influence the droplet size and the stability of W/O emulsions. The relationship between the droplet size and emulsion stability was also investigated.

1. The general trend observed was that the stability increased with decreasing droplet size, in agreement with previous reports. This behavior could be due to the low coalescence rate at smaller droplet sizes. However, the opposite behavior was observed when low stability was observed for smaller droplet sizes (at high waterphase fraction and low oil-phase fraction); this phenom- 
enon requires further investigation. The droplet size was found to be correlated with different factors.

2. The droplet size was found to decrease with increasing mixing speed: an $87 \%$ decrease was achieved when the mixing speed was increased from 500 to $1500 \mathrm{rpm}$. However, a slight decrease (15\%) was observed when the mixing speed was increased above $1500 \mathrm{rpm}$. The stability was enhanced at higher rates of mixing. Approximately $18 \%$ of the diesel was separated at $500 \mathrm{rpm}$, whereas no separation occurred at $2000 \mathrm{rpm}$.

3. The droplet size was established to increase with increasing WOR. Furthermore, the increase in the WOR resulted in an increase in the stability: $65 \%$ of the diesel separated when 30/70 WOR was used to form the system instead of 70/30 WOR.

4. Insignificant alteration in the droplet size and the stability was achieved when the formation brine, sea water, and field mixing water were used to prepare the emulsified gels, with high stability attained in the three cases. These observations likely result from high repulsion forces between the droplets of the dispersed phase at salinities $>20,000 \mathrm{mg} \mathrm{L}^{-1}$.

5. The increase in surfactant concentration was found to increase the stability and decrease the droplet size: an $87 \%$ decrease in the droplet size was achieved when the concentration was increased from 1 to $3 \mathrm{vol} \%$, which in turn led to a $56 \%$ decrease in the separated diesel. A further increase in the concentration from 3 to 6 vol $\%$ resulted in a $90 \%$ decrease in the separated diesel fraction. This behavior is associated with the number of emulsifier molecules adsorbed at the interface, causing a reduction in the interfacial tension between the continuous and dispersed phases.

6. The emulsified system stability decreased with increasing temperature. When the temperature was increased from $60^{\circ} \mathrm{C}\left(140{ }^{\circ} \mathrm{F}\right)$ to $120^{\circ} \mathrm{C}\left(248^{\circ} \mathrm{F}\right)$, the separated diesel increased by $91 \%$ after $1 \mathrm{~h}$. By contrast, no significant separation occurred at temperatures less than or equal to $60^{\circ} \mathrm{C}\left(140^{\circ} \mathrm{F}\right)$.

7. The emulsification reduced the gel strength and delayed the gelation process. When PAM/PEI was emulsified into diesel, a $61 \%$ reduction in the equilibrium storage modulus and a $2 \mathrm{~h}$ increase in the gelation time were recorded. However, when sufficient time was permitted for the emulsified system to completely separate, the ultimate gel strength could tentatively be attained. Hence, time is a critical parameter for the treatment design.

8. The cross-linking (gelation) rate in the unemulsified PAM/PEI was almost ten times higher than that in the emulsified gels with complete separation. This behavior was more pronounced in the case of stable emulsified PAM/PEI.
Acknowledgements I would like to thank King Fahd University of Petroleum \& Minerals for its support and King Abdulaziz City for Science and Technology for funding this work under project \# AT-30-291. Thanks and appreciations go to Dr. Ibnelwaleed Hussein for technical discussion and Mr. Abdlhaleim Mahmoud, lab assistant, who helped monitoring experiments.

Open Access This article is distributed under the terms of the Creative Commons Attribution 4.0 International License (http://creativeco mmons.org/licenses/by/4.0/), which permits unrestricted use, distribution, and reproduction in any medium, provided you give appropriate credit to the original author(s) and the source, provide a link to the Creative Commons license, and indicate if changes were made.

\section{References}

Al Tolaihy M, Bukhari DO, Wu AM (2010) Study on the optimization of de-scaling operations. In: Saudi Arabian Khuff Gas Wells', CORROSION 2010. San Antonio, Texas: NACE International, $\mathrm{p} 10$

Al-Muntasheri GA et al (2007) Viscoelastic properties of a high temperature cross-linked water shut-off polymeric gel. J Pet Sci Eng 55(1-2):56-66. https://doi.org/10.1016/J.PETROL.2006.04.004

Al-Mutairi SH, Hill AD, Nasr-El-Din HA (2007) Effect of droplet size, emulsifier concentration and acid volume fraction on the rheological properties and stability of emulsified acids. European formation damage conference. Society of Petroleum Engineers, Scheveningen, The Netherlands, p 16. https://doi. org/10.2118/107741-MS

Al-Mutairi SH et al (2009) Effect of droplet size on the reaction kinetics of emulsified acid with calcite. SPE J Soc Pet Eng 14(04):606-616. https://doi.org/10.2118/112454-PA

Al-Yaari M, Hussein IA et al (2013) Pressure drop reduction of stable emulsions: role of aqueous phase salinity. SPE Saudi Arabia Section Technical Symposium and Exhibition. Society of Petroleum Engineers, Al-Khobar, Saudi Arabia, p 11. https:// doi.org/10.2118/168078-MS

Al-Yaari M, Al-Sarkhi A et al (2013) Pressure drop reduction of stable water-in-oil emulsion flow: role of water fraction and pipe diameter. International Petroleum Technology Conference. International Petroleum Technology Conference, Beijing, China, p 9. https://doi.org/10.2523/IPTC-16883-MS

Al-Yaari M, Hussein IA, Al-Sarkhi A (2014) Pressure drop reduction of stable water-in-oil emulsions using organoclays. Appl Clay Sci 95:303-309. https://doi.org/10.1016/J.CLAY.2014.04.029

Anderson CD, Daniels ES (2003) Emulsion polymerisation and latex applications: Rapra review reports. https://www.freewebs.com/ amrodyab/emulsionpolymerizationand latex applications.pdf. Accessed 6 Dec 2018

Aveyard R, Binks BP, Fletcher PDI (1989) Interfacial tensions and aggregate structure in pentaethylene glycol monododecyl ether/ oil/water microemulsion systems. Langmuir Am Chem Soc 5(5):1210-1217. https://doi.org/10.1021/la00089a015

Becher P (1996) Encyclopedia of emulsion technology, vol 4. M. Dekker, New York. https://www.crcpress.com/Encyclopedia-ofEmulsion-Technology-Volume-4/Schuster/p/book/9780824793 807. Accessed 7 Dec 2018

Binks BP, Rocher A (2009) Effects of temperature on water-inoil emulsions stabilised solely by wax microparticles. J Colloid Interface Sci 335(1):94-104. https://doi.org/10.1016/J. JCIS.2009.03.089 
Clark CE, Veil JA (2009) Produced water volumes and management practices in the United States. Argonne National Laboratory, Argonne. https://doi.org/10.2172/1007397

Crenshaw PL, Flippen FF (1968) Stimulation of the deep Ellenburger in the Delaware Basin. J Pet Technol Soc Pet Eng 20(12):13611370. https://doi.org/10.2118/2075-PA

Dean SW, Greaves MR, Knoell JC (2009) A comparison of the performance of environmentally friendly anhydrous fire resistant hydraulic fluids. J ASTM Int ASTM Int 6(10):102192. https:// doi.org/10.1520/JAI102192

Ebeltoft H, Majeed Y, Sœrgärd E (2001) Hydrate control during deepwater drilling: overview and new drilling-fluids formulations. SPE Drill Complet Soc Pet Eng 16(01):19-26. https://doi. org/10.2118/68207-PA

El-Karsani KS et al (2014) Gelation kinetics of PAM/PEI system. J Therm Anal Calorim 116(3):1409-1415. https://doi.org/10.1007/ s10973-014-3754-y

El-Karsani KS et al (2015a) Gelation of a water-shutoff gel at high pressure and high temperature: rheological investigation. SPE J. https://doi.org/10.2118/173185-PA

El-Karsani KSM et al (2015b) Gelation of a water-shutoff gel at high pressure and high temperature: rheological investigation. SPE J 20(05):1103-1112. https://doi.org/10.2118/173185-PA

Fattah WA, Nasr-El-Din HA (2010) Acid emulsified in xylene: a costeffective treatment to remove asphalting deposition and enhance well productivity. SPE Prod Oper Soc Pet Eng 25(02):151-154. https://doi.org/10.2118/117251-PA

Friberg S, Larsson K, Sjöblom J (2004) Food emulsions. Marcel Dekker. https://www.crcpress.com/Food-Emulsions/Friberg-LarssonSjoblom/p/book/9780824746964. Accessed 7 Dec 2018

Guo J, Liu Q, Li M, Wu Z, Christy A (2006) The effect of alkali on crude oil/water interfacial properties and the stability of crude oil emulsions. Colloids Surf A 273:213-218

Hibbeler JC, Rae PJ (2005) The environmental benefits of reducing unwanted water production. SPE Asia Pacific Health, Safety and Environment Conference and Exhibition. Society of Petroleum Engineers, Kuala Lumpur, Malaysia, p 7. https://doi. org/10.2118/96582-MS

Joshi H et al (2012) A study of various factors determining the stability of molecules. Adv Pure Appl Chem 7(1). http://www.worldscien cepublisher.org. Accessed 7 Dec 2018

Kalfayan LJ, Dawson JC (2004) Successful implementation of resurgent relative permeability modifier (RPM) technology in well treatments requires realistic expectations. SPE annual technical conference and exhibition. Society of Petroleum Engineers, Houston, Texas, p 5. https://doi.org/10.2118/90430-MS

Kasapis S, Norton IT, Ubbink JB (2009) Modern biopolymer science: bridging the divide between fundamental treatise and industrial application. Elsevier, Oxford

Kokal SL (2005) Crude oil emulsions: a state-of-the-art review. SPE Prod Facil Soc Pet Eng 20(01):5-13. https://doi. org/10.2118/77497-PA

Lachman L, Lieberman HA, Kanig JL (1986) The Theory and practice of industrial pharmacy. Lea \& Febiger. https://books.googl e.com.sa/books/about/The_Theory_and_Practice_of_Industrial _Ph.html?id=p_VsAAAAMAAJ\&redir_esc=y. Accessed 7 Dec 2018

Lawhon CP, Evans WM, Simpson JP (1967) Laboratory drilling rate and filtration studies of emulsion drilling fluids. J Pet Technol Soc Pet Eng 19(07):943-948. https://doi.org/10.2118/1695-PA

Ling NNA et al (2018) Quantifying the effect of salinity on oilfield water-in-oil emulsion. Energy Fuels Am Chem Soc 32(9):1004210049. https://doi.org/10.1021/acs.energyfuels.8b02143

Mclean JD, Kilpatrick PK (1997) Effects of asphaltene solvency on stability of water-in-crude-oil emulsions. J Colloid Interface Sci
189:242-253. http://citeseerx.ist.psu.edu/viewdoc/download?do $\mathrm{i}=10.1 .1 .528 .4490 \& \mathrm{rep}=$ rep1\&type $=$ pdf. Accessed 7 Dec 2018

Mohamed AIA et al (2015) DSC investigation of the gelation kinetics of emulsified PAM/PEI system. J Therm Anal Calorimetry 122(3):1117-1123. https://doi.org/10.1007/s10973-015-4965-6

Montserrat $^{\ddagger} \mathrm{F}$ et al (2007) Effect of salinity, temperature, water content, and $\mathrm{ph}$ on the microwave demulsification of crude oil emulsions ${ }^{\dagger}$. Am Chem Soc. https://doi.org/10.1021/EF0603885

Navarrete RC, Miller MJ, Gordon JE (1998) Laboratory and theoretical studies for acid fracture stimulation optimization. SPE Permian Basin oil and gas recovery conference. Society of Petroleum Engineers, Midland, Texas, p 18. https://doi.org/10.2118/39776-MS

Osemeahon SA (2011) Copolymerization of methylol urea with ethylol urea resin for emulsion paint formulation. Afr J Pure Appl Chem 5(7):204-211. http://www.academicjournals.org/AJPAC. Accessed 7 Dec 2018

Patel AD (1999) Reversible invert emulsion drilling fluids: a quantum leap in technology. SPE Drill Complet Soc Pet Eng 14(04):274279. https://doi.org/10.2118/59479-PA

Rai N, Pandey IP (2013) Study of some physiochemical factors determining emulsion stability with mixed emulsifiers. J Ind Res Technol 3(1):12-16. http://www.hgpub.com/index_files/jirtpdf/ jirt.2229-9467.2013.0301.1216.3.pdf. Accessed 7 Dec 2018

Sayed MA, Nasr-El-Din HA (2011) Elastic properties of emulsified acids: effect of emulsifier concentration and temperature. SPE/ DGS Saudi Arabia Section Technical Symposium and Exhibition. Society of Petroleum Engineers, Al-Khobar, Saudi Arabia, p 14. https://doi.org/10.2118/149074-MS

Sayed M, Nasr-El-Din HA, Nasrabadi H (2013) Reaction of emulsified acids with dolomite. J Can Pet Technol Soc Pet Eng 52(03):164175. https://doi.org/10.2118/151815-PA

Schneider FN, Owens WW (1982) Steady-state measurements of relative permeability for polymer/oil systems. Soc Pet Eng J Soc Pet Eng 22(01):79-86. https://doi.org/10.2118/9408-PA

Seright RS (2009) Disproportionate permeability reduction with pore-filling gels. SPE J Soc Pet Eng 14(01):5-13. https://doi. org/10.2118/99443-PA

Sparlin DD (1976) An evaluation of polyacrylamides for reducing water production (includes associated papers 6561 and 6562). J Pet Technol Soc Pet Eng 28(08):906-914. https://doi. org/10.2118/5610-PA

Stavland A et al (1997) Disproportionate permeability reduction is not a Panacea. SPE European formation damage conference. Society of Petroleum Engineers, The Hague, Netherlands, p 10. https:// doi.org/10.2118/38195-MS

Stavland A et al (2006) How to apply a blocking gel system for bullhead selective water shutoff: from laboratory to field. SPE/DOE Symposium on Improved Oil Recovery. Society of Petroleum Engineers, Tulsa, Oklahoma, USA, p 12. https://doi.org/10.2118/99729 -MS

Strassner JE (1968) Effect of pH on interfacial films and stability of crude oil-water emulsions. J Pet Technol Soc Pet Eng 20(03):303312. https://doi.org/10.2118/1939-PA

Tamilvanan S et al (2016) Manufacturing techniques and excipients used during the formulation of oil-in-water type nanosized emulsions for medical applications. J Excipients Food Chem 1(1):1138. https://jefc.scholasticahq.com/article/1138-manufacturing-techn iques-and-excipients-used-during-the-formulation-of-oil-in-water -type-nanosized-emulsions-for-medical-applications. Accessed 7 Dec 2018

Taylor KC, Nasr-El-Din HA (2001) Laboratory evaluation of in-situ gelled acids for carbonate reservoirs. SPE Annual Technical Conference and Exhibition. Society of Petroleum Engineers, New Orleans, Louisiana, p 10. https://doi.org/10.2118/71694-MS

Weiss J (2002) Emulsion stability determination. Curr Protoc Food Anal Chem. https://doi.org/10.1002/0471142913.fad0304s03 
Winsor PA (1948) Hydrotropy, solubilisation and related emulsification processes. Trans Faraday Soc R Soc Chem 44(0):376. https://doi. org/10.1039/tf9484400376

Zaitoun A et al (1999) Water shutoff by relative permeability modifiers: lessons from several field applications. SPE Annual Technical Conference and Exhibition. Society of Petroleum Engineers, Houston, Texas, p 14. https://doi.org/10.2118/56740-MS
Publisher's Note Springer Nature remains neutral with regard to jurisdictional claims in published maps and institutional affiliations. 